\title{
BMJ Open Prevalence of anxiety and depressive symptoms and their association with multimorbidity and demographic factors: a community-based, cross- sectional survey in Karachi, Pakistan
}

\author{
Salima Farooq, ${ }^{1}$ Tahir Khan $\left(10,{ }^{2}\right.$ Sidra Zaheer, ${ }^{2}$ Kashif Shafique ${ }^{2,3}$
}

To cite: Farooq S, Khan T, Zaheer S, et al. Prevalence of anxiety and depressive symptoms and their association with multimorbidity and demographic factors: a community-based, crosssectional survey in Karachi, Pakistan. BMJ Open 2019;9:e029315. doi:10.1136/ bmjopen-2019-029315

- Prepublication history for this paper is available online. To view these files, please visit the journal online (http://dx.doi. org/10.1136/bmjopen-2019029315).

Received 18 March 2019 Revised 16 0ctober 2019 Accepted 23 October 2019

Check for updates

(c) Author(s) (or their employer(s)) 2019. Re-use permitted under CC BY-NC. No commercial re-use. See rights and permissions. Published by BMJ.

1 Institute of Nursing, Aga Khan University Faculty of Health Sciences, Karachi, Pakistan

${ }^{2}$ School of Public Health, Dow University of Health Sciences, Karachi, Pakistan

${ }^{3}$ Institute of Health and Wellbeing, University of Glasgow, Glasgow, UK

Correspondence to

Dr Tahir Khan;

tahir.khan@duhs.edu.pk

\section{ABSTRACT}

Objective This study aimed to estimate the prevalence of anxiety and depressive symptoms and their association with multimorbidity and the demographic characteristics of adults aged 30 years and above in Karachi, Pakistan.

Design Observational cross-sectional study.

Study setting and participants The study was carried out among a general population aged 30 years and above residing in the Gulshan-e-lqbal town of Karachi, Pakistan. The study participants were recruited using the systematic random sampling approach based on the inclusion criteria. The data collected from 2867 participants were analysed. Main outcome measures The primary outcome of the study was the prevalence of anxiety and depressive symptoms, measured with the Aga Khan University Anxiety Depression Scale. The secondary outcome was the association of anxiety and depressive symptoms with multimorbidity as well as with the sociodemographic characteristics of the participants, using binary logistic regression.

Results Out of 2867 individuals, $27.4 \%$ reported having anxiety and depressive symptoms. The multivariate logistic regression model revealed that the presence of multimorbidity (adjusted OR $(\mathrm{AOR})=1.33,95 \% \mathrm{Cl} 1.11$ to 1.58), female gender ( $A O R=2.40,95 \% \mathrm{Cl} 2.01$ to 2.87 ), illiteracy ( $\mathrm{AOR}=1.51,95 \% \mathrm{Cl} 1.09$ to 2.07 ), more children (AOR $=0.74,95 \% \mathrm{Cl} 0.59$ to 0.93 ) and visiting a faith healer ( $A O R=2.29,95 \% \mathrm{Cl} 1.82$ to 2.88) were the significant factors associated with anxiety and depressive symptoms. Conclusion This study revealed a moderately high prevalence of anxiety and depressive symptoms among adults aged 30 years and above in Karachi, Pakistan. The key variables associated with anxiety and depressive symptoms were multimorbidity, female gender, lower level of education, more children and visiting faith healers.

\section{INTRODUCTION}

Mental illness, anxiety and depressive symptoms are major public health issues. Globally, $14 \%$ of people suffer from mental illnesses. ${ }^{1}$ More than three-quarters of these people belong to low-income and middle-income countries. $^{2}$ The magnitude of anxiety and
Strengths and limitations of this study

- The study sample was a large, community-based, ethnically and socioeconomically diverse group of population.

- A validated screening tool (Aga Khan University Anxiety Depression Scale) assessed the presence of anxiety and depressive symptoms, which enhanced the internal validity of the research.

- Inferences could not be drawn on causality of associations due to the nature of the design.

- The study data were self-reported; hence, the results should be interpreted cautiously.

depression is on the rise among the general population. Additionally, individuals with chronic diseases are at even higher risk of developing anxiety and depressive symptoms. ${ }^{3-6}$ In fact, depression has been ranked as the fourth leading cause of disease burden. ${ }^{7}$ Moreover, it is predicted that by the year 2020, it will be the second leading cause of disability and death, after cardiovascular disorders. $^{7-10}$

Multimorbidity is the co-occurrence of two or more chronic diseases, such as cancer, diabetes, hypertension, stroke, asthma, heart disease, arthritis or osteoporosis, within an individual. ${ }^{911} 12$ Research studies suggest that one in four adults in developed countries has multimorbidity. ${ }^{13} 1415$ One study claims that $52 \%$ of people, between the ages of 21 and 84 years, are suffering from multimorbidity, ${ }^{16}$ whereas a study conducted by Garin $e a^{17}$ in 2014 found a burden of $67 \%$ multimorbidity among elderly Spanish women. Furthermore, among developing countries, in Bangladesh, the prevalence of multimorbidity is $53.8 \%$ among older adults, ${ }^{11}$ and in India the burden of multimorbidity is at $22 \%,{ }^{18}$ while among the Pakistani population aged 
18 years and older it was reported at $4.9 \% .^{19}$ Thus, the prevalence of multimorbidity varies from $4.9 \%$ to $67 \%$ in various countries. ${ }^{19-21}$

The reasons for the variation in prevalence could be due to differences in the definition of multimorbidity, number of chronic conditions included in the studies, diagnostic criteria for medical conditions, as well as the study's sample size and population characteristics. Literature suggests that the prevalence of multimorbidity increases with age, ${ }^{12} 22$ and this burden is reported to be more common in women. Additionally, individuals living in underprivileged areas are at a higher risk of developing multimorbidity. ${ }^{23}$

Healthcare providers often face challenges when dealing with clients who have multimorbidity, along with anxiety and depressive symptoms. ${ }^{24}{ }^{25}$ As multimorbidity conditions such as diabetes, hypertension, stroke, asthma, arthritis and osteoporosis have synergetic effects with anxiety and depression, they increase the probability of disabilities among patients. ${ }^{3}$ Moreover, individuals with multimorbidity need to deal with multiple treatment recommendations. ${ }^{6}$ In addition, the presence of anxiety and depression with multimorbidity leads to increased utilisation of healthcare facilities. This consequently leads to financial healthcare burden and poorer health outcomes. ${ }^{2} 132627$ Thus, anxiety and depression, with multimorbidity, are linked with a $50 \%-100 \%$ increase in the utilisation of health services and cost. ${ }^{28}$

Anxiety and depression are extremely common and alarmingly underdiagnosed healthcare problems especially in low-income and middle-income countries. In addition, they are associated with social stigma and self-stigma, which act as a barrier to the mental helpseeking behaviour of individuals suffering from mental health issues, which leads to an even greater public health concern. Furthermore, anxiety and depression are specifically reported to be common in individuals with multimorbidity. ${ }^{36}$ However, the studies that report these associations have mostly been conducted in highincome countries. To the best of our knowledge, no such population-based study has been reported from Pakistan as yet. In a resource-limited setting like Pakistan, underdiagnosis of mental illnesses can cause potential delay in the initiation of treatment. Hence, it is of utmost importance that anxiety and depression be screened in adults suffering from multimorbidity in order to reduce the burden of complications and suboptimal adherence to the treatment of multimorbidity conditions. Moreover, due to scarcity of literature from Pakistan, quantification of the association between anxiety and depression and multimorbidity within the Pakistani population is an urgent need. In this study, it was hypothesised that there is an association between anxiety and depressive symptoms and multimorbidity among the Pakistani population. Therefore, the purposes of this study were to estimate the prevalence of anxiety and depressive symptoms and to determine their association with multimorbidity and demographic factors among adults aged 30 years and above in Karachi, Pakistan.

\section{METHODOLOGY}

This study was part of a larger community-based research project titled 'The Burden of Multimorbidity, Its Patterns and Consequences on Health and Well-Being: The IMPACT Study', conducted in 2015-2016.

\section{Study design}

An observational cross-sectional study was conducted to estimate the burden of anxiety and depressive symptoms, and to identify their associated factors.

\section{Study population}

The study population comprised all adults aged 30 years and above living in the Gulshan-e-Iqbal town of Karachi, Pakistan. This particular age group was selected as chronic medical conditions are more prevalent in this group.

\section{Inclusion criteria}

The study included all persons aged 30 years and above who were residents of the Gulshan-e-Iqbal town of Karachi, Pakistan, and who signed the consent form to take part in the study.

\section{Sample size calculation}

To meet the objective of this study, the sample size was calculated using an online version of the OpenEpi calculator. The prevalence of anxiety and depression is reported to be $30 \%-50 \%$ among adults in Pakistan. ${ }^{29} 30$ With a $2 \%$ margin of error and $95 \%$ confidence level, the required sample size was 2401 participants. Similarly, to attain the secondary objective (association of anxiety and depressive symptoms with multimorbidity), keeping CI at $95 \%$, with $90 \%$ power, 1:1 ratio of non-depressed and depressed individuals, OR of 1.55, and with proportion of multimorbidity among non-depressed taken as $10 \%,{ }^{31}$ the required sample size was 2148 individuals. In order to account for missing values, the higher sample size (2401) was chosen. Ultimately, 3250 individuals were recruited for data collection.

\section{Sampling technique}

The present study was conducted in the Gulshan-e-Iqbal town of Karachi, Pakistan. A sample of 3250 participants were recruited using the systematic random sampling technique. This sample was achieved using proportionate estimates of the number of individuals in 13 union councils (UCs) in the selected town. The proportionate allocation method was used in order to allocate appropriate weightage to each UC. Within each UC, blocks of houses were selected with a random start, where every 109th (kth sampling interval) household was selected. Individuals within these households who met the eligibility criteria were included in the study. 


\section{Data collection}

Data were collected from participants by interviews using a structured questionnaire; the questionnaire was developed after a thorough literature review. The questionnaire was designed to collect data related to sociodemographic information including age, gender, marital status, educational status, employment status, mother tongue, number of family members and information about housing, presence of any chronic disease, and living conditions of each participant. Participants were interviewed by trained data collectors. Anthropometric measurements as well as blood pressure were measured by trained health professionals, which mainly included doctors and nurses, who were involved in data collection.

\section{Dependent variable}

The Aga Khan University Anxiety Depression Scale (AKUADS) was used to assess the anxiety and depressive symptoms of the participants. This study used the Urdu version of the AKUADS, which had been validated in a previous research. ${ }^{32}$ The value of the reliability coefficient tool in the study population was 0.93 . This tool had a total of 25 questions, and for each of the questions the participants could choose an answer from never (scored as 0 ), sometimes (scored as 1), often (scored as 2) and always (scored as 3). A cumulative cut-off score of 20 or greater on this scale was used to label anxiety and depression. At a cut-off score of 20, the AKUADS had a sensitivity of $66 \%$ and a specificity of $79 \% .^{3233}$

\section{Independent variables}

The presence of disease was assessed by a combination of self-reported diagnosis, medication use and laboratory findings. Self-reported disease was determined by the question 'Have you ever been told by a doctor, nurse, or other health professional that you have hypertension, obesity, dyslipidemia, diabetes, heart diseases (Myocardial Infarction and/or chronic ischemic heart diseases), stroke, migraines, asthma and chronic obstructive pulmonary disease [COPD], anemia, thyroid disease, diseases of bones and joints, dyspepsia/peptic ulcer, hepatitis B or C, chronic kidney diseases including stones, cancer, and/or disability?'

Individuals with two or more chronic diseases (excluding anxiety and depression) were labelled as having 'multimorbidity', and others who reported one or no chronic medical disease were considered as having 'no multimorbidity'. Set criteria were used to define chronic diseases, such as hypertension, obesity, diabetes and dyspepsia. A person was said to be hypertensive if they had a high systolic blood pressure $(>140 \mathrm{~mm} \mathrm{Hg})$ or a high diastolic blood pressure $(>90 \mathrm{~mm} \mathrm{Hg})$. A person was considered obese if they had a calculated body mass index $\geq 30.0 \mathrm{~kg} /$ $\mathrm{m}^{2}$. A person was said to be diabetic if blood glucose level was $\geq 200 \mathrm{mg} / \mathrm{dL}$. A person was considered to have dyspepsia if they had four or more symptoms of dyspepsia for at least 6 months, based on the Leeds Dyspepsia Questionnaire.
Besides disease-related variables, other sociodemographic variables were also measured, such as household income, occupation and education. This variable was initially taken as continuous variable, such as what is your monthly income (in Pakistani rupees). Then it was further classified into quintiles, that is, <16000, 16001-24 999, 25000-39 999, 40000-54 999 and 55000 rupees and above. The occupation of all the participants was also assessed as a categorical variable and categorised as unemployed, unskilled worker, skilled worker, labour worker, non-manual worker and professional office job. Data on education were collected as the total number of years of full education, which were then categorised into five categories: no education ( 0 years or those who never attended school), primary (1-5 years), secondary (6-10 years), higher education (11-14 years) and postgraduate ( $\geq 15$ years).

\section{Statistical analysis}

Variables were precoded and data were entered and analysed in SPSS V.19.0. Descriptive statistics were calculated in the form of frequencies and percentages for categorical variables. Descriptive statistics were calculated in order to estimate the prevalence of anxiety and depressive symptoms. Univariate and multivariate binary logistic regressions were used to assess the associations between anxiety and depressive symptoms and multimorbidity. ORs and their 95\% CIs were also calculated. The multivariate model was adjusted only for variables with $p$ values $<0.250$ in univariate analysis, using a stepwise logistic regression method, following the Hosmer and Lemeshow protocol. ${ }^{34}$ Moreover, this manuscript followed the crosssectional reporting guidelines of the Strengthening the Reporting of Observational Studies in Epidemiology. ${ }^{35}$

\section{Patient and public involvement}

In the current study, patients were not involved in the research question, study design, outcome measures and recruitment.

\section{RESULTS}

A total of 3250 participants were interviewed. However, the data were analysed using information from 2867 study participants. Of the total, 383 participants were excluded due to missing information on the following variables: anxiety and depression symptoms $(n=06)$, presence of multimorbidity $(n=09)$, respondents' age $(n=06)$, gender $(n=08)$, education $(n=48)$, income $(n=81)$, occupation $(n=72)$, marital status $(n=05)$, number of children $(\mathrm{n}=67)$, ethnicity $(\mathrm{n}=09)$, home status $(\mathrm{n}=14)$, smoking status $(n=66)$ and visiting faith healer $(n=93)$.

The mean age of the 2867 study participants was 45.5 years ( $\mathrm{SD} \pm 11.7$ years). The male to female ratio was approximately equal, $51.5 \%(\mathrm{n}=1477)$ male and $48.5 \%$ $(n=1390)$ female. Regarding the educational level of the participants, $14 \%(n=404)$ had no formal education, 38.3\% $(n=1098)$ had higher education and $20.4 \%$ 
$(\mathrm{n}=585)$ had postgraduate education. In addition, $22.3 \%$ $(\mathrm{n}=638)$ reported their monthly household income to be less than 16000 rupees, while $18.2 \% \quad(n=523)$ claimed their monthly income to be more than 55000 rupees. The majority of participants $(42 \%, \mathrm{n}=1205)$ had professional jobs, $14 \% \quad(n=389)$ were labourers and $17 \% \quad(n=484)$ were unemployed. Anxiety and depressive symptoms and multimorbidity were reported by $27.4 \% \quad(\mathrm{n}=786)$ and $50.2 \%(\mathrm{n}=1440)$ of the study participants, respectively. The sociodemographic and other characteristics of the participants are shown in table 1.

The adjusted model revealed that participants who had multimorbidity had $33 \%$ increased odds of being anxious and depressed (adjusted OR (AOR) $=1.33,95 \%$ CI 1.11 to 1.58), as compared with those who did not report multimorbidity. Moreover, the odds of having anxiety and depressive symptoms were 2.40 times higher among female participants, as compared with male participants $(\mathrm{AOR}=2.40,95 \% \mathrm{CI} 2.01$ to 2.87), and the odds of having anxiety and depressive symptoms were $51 \%$ higher among participants who had no formal education (AOR=1.51, 95\% CI 1.09 to 2.07), as compared with participants who had postgraduate education. Furthermore, the odds of being anxious and depressed were 1.34 times higher among participants who did labour work as compared with participants who were doing professional office jobs (AOR=1.34, 95\% CI 1.00 to 1.79). Also, study participants who had one to two children were at $32 \%$ reduced odds (AOR $=0.68,95 \% \mathrm{CI} 0.56,0.84)$ and those who had more than two children were at $26 \%$ reduced odds (AOR $=0.74,95 \% \mathrm{CI} 0.59$ to 0.93 ) of having anxiety and depressive symptoms, as compared with participants who had no children. Furthermore, subjects belonging to the Punjabi ethnicity (AOR=1.66, 95\% CI 1.16 to 2.37 ) had $66 \%$ increased odds of being anxious and depressed as compared with Sindhi subjects. In addition, in subjects who were visiting a faith healer, the odds of exhibiting anxiety and depressive symptoms were 2.29 times (AOR=2.29, 95\% CI 1.82 to 2.88), as compared with participants who did not visit a faith healer (table 2).

Table 3 shows the estimated association of anxiety and depressive symptoms and the number of chronic diseases. The anxiety and depressive symptoms were significantly associated with increasing number of chronic diseases. The odds of anxiety and depressive symptoms were highest among individuals with four chronic diseases (AOR=1.92, 95\% CI 1.33 to 2.78) and more than four chronic diseases (AOR=2.62, 95\% CI 1.66 to 4.13), as compared with healthy individuals, when adjusted for other variables (table 3 ).

\section{DISCUSSION}

This study showed that nearly a quarter of the study participants had symptoms of anxiety and depression. Moreover, it illustrated that the presence of multimorbidity, female gender, lower level of education, more children,
Table 1 Sociodemographic and other characteristics of participants $(\mathrm{N}=2867)$

\begin{tabular}{lc}
\hline Characteristics & $\mathbf{n}(\%)$ \\
\hline $\begin{array}{l}\text { Anxiety and depressive symptoms } \\
\text { No }\end{array}$ & $2081(72.6)$ \\
\hline Yes & $786(27.4)$ \\
\hline Presence of multimorbidity & \\
\hline No & $1427(49.8)$ \\
\hline Yes & $1440(50.2)$ \\
\hline Age (years) & \\
\hline $30-39$ & $1062(37.0)$ \\
\hline $40-49$ & $816(28.5)$ \\
\hline $50-59$ & $570(19.9)$ \\
$60-69$ & $293(10.2)$ \\
\hline 70 & $126(4.4)$ \\
Gender & \\
\hline Male & $1477(51.5)$ \\
\hline Female & $1390(48.5)$ \\
\hline
\end{tabular}

Education

\begin{tabular}{lc} 
No education & $404(14.1)$ \\
Primary & $133(4.6)$ \\
Secondary & $647(22.6)$ \\
Higher/graduate & $1098(38.3)$ \\
\hline Postgraduate & $585(20.4)$ \\
Income (rupees) & \\
$<16000$ & $638(22.3)$ \\
16001-24 999 & $426(14.9)$ \\
$25000-39999$ & $636(22.2)$ \\
$40000-54999$ & $644(22.5)$ \\
\hline 55000 & $523(18.2)$ \\
Occupation & \\
Unemployed & $484(16.9)$ \\
Unskilled worker & $243(8.5)$ \\
Skilled worker & $250(8.7)$ \\
\hline Labour work & $389(13.6)$ \\
\hline Non-manual work & $296(10.3)$ \\
\hline Professional office job & $1205(42)$ \\
Marital status & \\
\hline Never married & $272(9.5)$ \\
Currently married & $2437(85.0)$ \\
\hline Widowed/separated/divorced & $158(5.5)$ \\
Number of children & \\
\hline No child & $1250(43.6)$ \\
\hline 1-2 & $974(34.0)$ \\
\hline Ethnicity & $643(22.4)$ \\
\hline Sindhi & $402(14.0)$ \\
\hline
\end{tabular}

Continued 


\begin{tabular}{lc}
\hline Table 1 Continued & n (\%) \\
\hline Characteristics & $318(11.1)$ \\
\hline Punjabi & $94(3.3)$ \\
Balochi & $176(6.1)$ \\
Pashtu & $1534(53.5)$ \\
Urdu & $343(12.0)$ \\
Others & \\
Home status & $1595(55.6)$ \\
Own & $1155(40.3)$ \\
Rent & $117(4.1)$ \\
Other arrangement & \\
Smoking status & $2323(81.0)$ \\
No & $544(19.0)$ \\
Yes & \\
Visiting faith healer & $2471(86.2)$ \\
No & $396(13.8)$ \\
\hline Yes &
\end{tabular}

ethnicity and visiting a faith healer were significantly associated with anxiety and depressive symptoms.

The current study used a screening tool (AKUADS) to assess the presence of anxiety and depressive symptoms. According to the findings, the overall prevalence of anxiety and depressive symptoms was $27.4 \%$. This has previously been reported to be around $10 \%$ and $44 \%$ in developed and developing countries, respectively. ${ }^{36} 37$ Islam $e t a l,{ }^{38}$ in their study conducted in 2003, found a $28 \%$ prevalence of depression among the Bangladesh population. In the USA, the prevalence of anxiety and depression was reported to be $16.2 \% .{ }^{39}$ Papadopoulos $e t$ $a l^{t 0}$ reported that the prevalence of depression in Greece was $27 \%$, whereas in India the prevalence of depression was found to be $28 \% .{ }^{41}$ However, in Pakistan, the prevalence of depression and anxiety has been found to be around 30\%-50\%. ${ }^{29} 363742$ A plausible reason for the difference in the prevalence of anxiety and depression could be different inclusion criteria, sample sizes, recruitment methods, various screening tools and cut-off points that were employed in these diverse studies. ${ }^{21}$

In the past decade, several research studies have established a strong relationship between anxiety and depression and multimorbidity. ${ }^{49} 31$ The findings of the present study were in concurrence with the previous studies showing a significant association between anxiety and depression and multimorbidity ${ }^{6{ }^{4}{ }^{4-46}}$ A probable reason could be that mental illness is linked with unhealthy habits, such as smoking, poor self-care, lack of physical activities and poor medication compliance. ${ }^{44} 47$

In the present study, anxiety and depressive symptoms were found to be strongly associated with women. The prevalence of anxiety and depressive symptoms was found to be 2.5 times higher in women than in men. Likewise, previous studies have also revealed a positive association
Table 2 Univariate and multivariate analyses of factors associated with anxiety and depressive symptoms among adults $(\mathrm{N}=2867)$

\begin{tabular}{lllll}
\hline & \multicolumn{4}{c}{ Anxiety and depressive symptoms } \\
\cline { 2 - 5 } Characteristics & COR & $95 \% \mathbf{C l}$ & AOR & $\mathbf{9 5 \%} \mathbf{C l}$ \\
\hline $\begin{array}{l}\text { Presence of } \\
\text { multimorbidity }\end{array}$ & & & & \\
$\quad$ No & 1 & & 1 & \\
Yes & 1.39 & 1.18 to 1.64 & 1.33 & 1.11 to 1.58 \\
\hline Age (years) & & & & \\
\hline $30-39$ & 1 & & - & \\
$40-49$ & 0.95 & 0.77 to 1.77 & - & \\
$50-59$ & 1.14 & 0.92 to 1.40 & - & \\
$60-69$ & 1.02 & 0.78 to 1.40 & - \\
$\geq 70$ & 1.26 & 0.85 to 1.88 & - \\
\hline
\end{tabular}

Gender

\begin{tabular}{|c|c|c|c|c|}
\hline Male & 1 & & 1 & \\
\hline Female & 2.58 & 2.17 to 3.05 & 2.40 & 2.01 to 2.87 \\
\hline \multicolumn{5}{|l|}{ Education } \\
\hline Postgraduate & 1 & & 1 & \\
\hline Higher/graduate & 0.89 & 0.71 to 1.13 & 0.86 & 0.67 to 1.09 \\
\hline Secondary & 1.15 & 0.89 to 1.48 & 1.05 & 0.78 to 1.40 \\
\hline Primary & 1.22 & 0.81 to 1.85 & 1.11 & 0.70 to 1.77 \\
\hline No education & 1.95 & 1.48 to 2.57 & 1.51 & 1.094 to 2.07 \\
\hline \multicolumn{5}{|l|}{ Income (rupees) } \\
\hline$>55000$ & 1 & & - & \\
\hline $40000-54999$ & 0.91 & 0.69 to 1.17 & - & \\
\hline 25000-39999 & 0.99 & 0.76 to 1.28 & - & \\
\hline $16001-24999$ & 1.08 & 0.81 to 1.43 & - & \\
\hline$<16000$ & 1.02 & 0.79 to 1.32 & - & \\
\hline \multicolumn{5}{|l|}{ Occupation } \\
\hline Professional office job & 1 & & 1 & \\
\hline Non-manual work & 0.78 & 0.58 to 1.06 & 0.81 & 0.58 to 1.13 \\
\hline Labour work & 1.22 & 0.95 to 1.57 & 1.34 & 1.00 to 1.79 \\
\hline Skilled worker & 1.15 & 0.85 to 1.55 & 1.29 & 0.93 to 1.78 \\
\hline Unskilled worker & 1.17 & 0.87 to 1.59 & 1.06 & 0.75 to 1.48 \\
\hline Unemployed & 0.85 & 0.71 to 1.14 & 0.90 & 0.68 to 1.18 \\
\hline \multicolumn{5}{|l|}{ Marital status } \\
\hline Currently married & 1 & & 1 & \\
\hline Never married & 0.78 & 0.58 to 1.05 & 0.87 & 0.62 to 1.17 \\
\hline $\begin{array}{l}\text { Widowed/separated/ } \\
\text { divorced }\end{array}$ & 1.45 & 1.03 to 2.03 & 1.02 & 0.72 to 1.48 \\
\hline
\end{tabular}

Number of children

\begin{tabular}{lllll} 
No child & 1 & & 1 & \\
\hline $1-2$ & 0.68 & 0.56 to 0.83 & 0.68 & 0.56 to 0.84 \\
$\begin{array}{l}\text { 3 and above } \\
\text { Ethnicity }\end{array}$ & 0.84 & 0.68 to 1.04 & 0.74 & 0.59 to 0.93 \\
\hline $\begin{array}{l}\text { Sindhi } \\
\text { Punjabi }\end{array}$ & 1 & & 1 & \\
\hline Balochi & 1.84 & 1.31 to 2.58 & 1.66 & 1.16 to 2.37 \\
\hline Pashtu & 1.26 & 0.74 to 2.14 & 1.32 & 0.76 to 2.30 \\
\hline
\end{tabular}

Continued 


\begin{tabular}{|c|c|c|c|c|}
\hline \multirow[b]{2}{*}{ Characteristics } & \multicolumn{4}{|c|}{ Anxiety and depressive symptoms } \\
\hline & COR & $95 \% \mathrm{Cl}$ & AOR & $95 \% \mathrm{Cl}$ \\
\hline Urdu & 1.45 & 1.11 to 1.89 & 1.35 & 1.00 to 1.81 \\
\hline Others & 1.84 & 1.32 to 2.56 & 1.52 & 1.07 to 2.17 \\
\hline \multicolumn{5}{|l|}{ Home status } \\
\hline Own & 1 & & - & \\
\hline Rent & 0.96 & 0.81 to 1.14 & - & \\
\hline Other arrangement & 0.70 & 0.44 to 1.10 & - & \\
\hline \multicolumn{5}{|l|}{ Smoking status } \\
\hline No & 1 & & - & \\
\hline Yes & 0.80 & 0.65 to 1.00 & - & \\
\hline \multicolumn{5}{|l|}{ Visiting faith healer } \\
\hline No & 1 & & 1 & \\
\hline Yes & 2.44 & 1.96 to 3.03 & 2.29 & 1.82 to 2.88 \\
\hline
\end{tabular}

For AOR, only variables with $\mathrm{p}$ value $<0.250$ in univariate analysis were entered into adjusted model using stepwise selection (presence of multimorbidity, gender, education, occupation, marital status, number of children, ethnicity and visiting faith healer).

AOR, adjusted OR;COR, unadjusted OR.

between anxiety, depression and gender. A research conducted by Mirza and Jenkins ${ }^{42}$ found that the prevalence of anxiety and depressive symptoms was $29 \%-66 \%$ among women, as compared with $10 \%-33 \%$ in men. Plausible reasons for the higher prevalence of anxiety and depression among women could be biological factors, socioeconomic disadvantages, deprivation of social status, maladaptive coping styles and lack of a support system for women in our country. ${ }^{48}$

The current study also found illiteracy as one of the potential risk factors among participants. Similarly,

Table 3 Univariate and multivariate analyses of anxiety and depressive symptom with number of chronic diseases among adults ( $\mathrm{N}=2867)$

\begin{tabular}{llllll}
\hline & \multicolumn{5}{c}{ Anxiety and depressive symptoms } \\
\cline { 2 - 6 } Characteristics & $\mathbf{n}(\%)$ & $\mathbf{C O R}$ & $\mathbf{9 5 \%} \mathbf{C l}$ & $\mathbf{A O R}$ & $\mathbf{9 5 \%} \mathbf{C l}$ \\
\hline Number of chronic diseases & & & & \\
\hline None & $152(24.6)$ & 1 & & 1 & \\
1 & $192(23.7)$ & 0.95 & 0.74 to & 0.89 & 0.69 to \\
& & & 1.21 & & 1.14 \\
\hline 2 & $181(25.5)$ & 1.05 & 0.81 to & 0.98 & 0.76 to \\
& & & 1.34 & & 1.27 \\
3 & $134(29.8)$ & 1.30 & 0.99 to & 1.20 & 0.90 to \\
& & & 1.71 & & 1.59 \\
4 & $76(42.2)$ & 2.24 & 1.58 to & 1.92 & 1.33 to \\
& & & 3.17 & & 2.78 \\
$5+$ & $51(50.0)$ & 3.06 & 1.99 to & 2.62 & 1.66 to \\
& & & 4.70 & & 4.13 \\
\hline
\end{tabular}

AOR for all variables with $p$ value $<0.250$ in univariate analysis (age, gender, education, occupation, marital status, number of children, ethnicity, home status, smoking status and visiting faith healer). AOR, adjusted OR;AOR, Adjusted Odds Ratio; COR, Crude/ unadjusted Odds Ratio. previous studies have found a strong association between low levels of education and anxiety and depressive symptoms. ${ }^{490}$ Among the literate population, education could be one of the factors that facilitate adaptive coping skills, and enables them to deal with distress situations and in improving their self-confidence, self-efficacy, social skills building and developing a sense of control over the environment. $^{51}$

According to the findings of the current study, participants who bore more children were less likely to develop anxiety and depressive symptoms. The plausible reason could be that parents tend to be positively engaged with their children and to be bound with their lives by giving them continuous love, time, support and commitment, which can all be coping strategies against distress. Having more children can also act as a buffer, considering the cultural dimension of the South Asian population where older children provide and ensure financial security for the family. ${ }^{52}$ Moreover, they also perform the role of a caretaker and/or may help with family household chores. This provides positive hope to the family that their future financial and social security are guaranteed and thus decreases anxiety and depression. In contrast, other studies have found that having more children is a risk factor for anxiety and depression among women. ${ }^{49} 53$

Our study also revealed that ethnicity of a participant is linked with anxiety and depressive symptoms. Subjects who were Punjabi were more likely to have anxiety and depressive symptoms. Consistent findings have been reported by previous studies that ethnicity was a significant risk factor for depression. ${ }^{54}{ }^{55}$ However, another study reported no association between these variables. ${ }^{53}$

A notable finding of the present study was that visiting a faith healer was positively associated with anxiety and depression in both genders. In the Pakistani culture, distressed individuals generally seek help from traditional healers or faith healers prior to visiting a doctor or a psychiatrist for their illness. A few probable reasons why people visit faith healers could be easy accessibility, availability and affordability, cultural beliefs, and the predominant stigma attached to the notion of mental illness. ${ }^{53} 56$ Moreover, in Pakistan, many people believe that mental illnesses are due to wrongdoings, being possessed, witchcraft and evil spirits; hence, the affected population consults these faith healers rather than doctors. Our result is consistent with a past study where it was reported that $16 \%$ of the Pakistani population first approach faith healers for their illness. ${ }^{57}$

\section{Strengths and limitations}

This is probably the first research that has determined an association between anxiety and depressive symptoms and multimorbidity among Pakistani population. Due to the cross-sectional nature of the study, inferences could not be determined on the causality of the relationship. Potential risk factors such as family history of psychiatric disorders, marital dissatisfaction, domestic violence, maladaptive coping, current life stressors and death of a 
loved one could not be addressed in the current study. Moreover, this study was based on self-reported information about multimorbidity and anxiety and depression.

\section{CONCLUSION}

This study suggests that almost a quarter of the study population had anxiety and depressive symptoms. Among women, anxiety and depressive symptoms are twice as common as compared with men. Early prevention through screening is the key measure for preventing the rising burden of mental disorders and their association with chronic physical conditions. Therefore, there is a dire need to create awareness regarding identification of symptoms of mental illness and to develop a proper referral system for essential treatment at the early stage of the disease, to avoid delayed presentation when the disease is more advanced.

Acknowledgements We would like to acknowledge the contributions of Ms Yasmin Parpio and Ms Ambreen Gowani in this research work findings of which have been published as an absract.https://stti.confex.com/stti/bc17/webprogram/ Paper86091.html

Contributors KS and SF conceived the research question and the design of this project. SF conducted all the literature reviews and manuscript drafting and review, and took part in data collection. TK and SZ helped in the data analysis and preparation of tables, and reviewed the manuscript. KS supervised the research project and conducted the final editing and review of the manuscript. The final version of this manuscript was seen and approved by all authors.

Funding The authors have not declared a specific grant for this research from any funding agency in the public, commercial or not-for-profit sectors.

Competing interests None declared.

Patient consent for publication Not required.

Ethics approval The study's proposal was approved by the Institutional Review Board (IRB) of the Dow University of Health Sciences (reference number: IRB-554/ DUHS/Approval/2015/04). Only individuals who provided written informed consent were interviewed. A referral plan for counselling was made for participants who scored 20 and above on the AKUADS.

Provenance and peer review Not commissioned; externally peer reviewed.

Data availability statement Data are available upon reasonable request by the corresponding author.

Open access This is an open access article distributed in accordance with the Creative Commons Attribution Non Commercial (CC BY-NC 4.0) license, which permits others to distribute, remix, adapt, build upon this work non-commercially, and license their derivative works on different terms, provided the original work is properly cited, appropriate credit is given, any changes made indicated, and the use is non-commercial. See: http://creativecommons.org/licenses/by-nc/4.0/.

\section{ORCID iD}

Tahir Khan http://orcid.org/0000-0002-0281-7650

\section{REFERENCES}

1. Yatham S, Sivathasan S, Yoon R, et al. Depression, anxiety, and post-traumatic stress disorder among youth in low and middle income countries: a review of prevalence and treatment interventions. Asian J Psychiatr 2018;38:78-91.

2. Jordans MJD, Kaufman A, Brenman NF, et al. Suicide in South Asia: a scoping review. BMC Psychiatry 2014;14:358.

3. Deschênes SS, Burns RJ, Schmitz N. Associations between depression, chronic physical health conditions, and disability in a community sample: a focus on the persistence of depression. $J$ Affect Disord 2015;179:6-13.

4. Winkler P, Horáček J, Weissová A, et al. Physical comorbidities in depression co-occurring with anxiety: a cross sectional study in the Czech primary care system. Int $J$ Environ Res Public Health 2015;12:15728-38.

5. Levinson D, Karger CJ, Haklai Z. Chronic physical conditions and use of health services among persons with mental disorders: results from the Israel National health survey. Gen Hosp Psychiatry 2008;30:226-32.

6. Gunn JM, Ayton DR, Densley K, et al. The association between chronic illness, multimorbidity and depressive symptoms in an Australian primary care cohort. Soc Psychiatry Psychiatr Epidemiol 2012;47:175-84.

7. Moussavi S, Chatterji S, Verdes E, et al. Depression, chronic diseases, and decrements in health: results from the world health surveys. Lancet 2007;370:851-8.

8. Mathers C, Fat DM, Boerma JT. The global burden of disease: 2004 update. World Health Organization, 2008.

9. O'Connor K, Vizcaino M, Ibarra JM, et al. Multimorbidity in a Mexican community: secondary analysis of chronic illness and depression outcomes. Int J Nurs (N Y) 2015;2:35-47.

10. World Health Organization. Depression and other common mental disorders: global health estimates, 2017.

11. Khanam MA, Streatfield PK, Kabir ZN, et al. Prevalence and patterns of multimorbidity among elderly people in rural Bangladesh: a crosssectional study. J Health Popul Nutr 2011;29:406.

12. Liddy C, Blazkho V, Mill K. Challenges of self-management when living with multiple chronic conditions: systematic review of the qualitative literature. Can Fam Physician 2014;60:1123-33.

13. Ahmadi B, Alimohammadian M, Yaseri M, et al. Multimorbidity: epidemiology and risk factors in the Golestan cohort study, Iran: a cross-sectional analysis. Medicine 2016;95:e2756.

14. Alaba O, Chola L. The social determinants of multimorbidity in South Africa. Int J Equity Health 2013;12:63-10.

15. Chatterji S, Byles J, Cutler D, et al. Health, functioning, and disability in older adults - present status and future implications. Lancet 2015;385:563-75.

16. Aarts S, den Akker Mvan, Bosma H, et al. The effect of multimorbidity on health related functioning: temporary or persistent? results from a longitudinal cohort study. $J$ Psychosom Res 2012;73:211-7.

17. Garin N, Olaya B, Perales J, et al. Multimorbidity patterns in a national representative sample of the Spanish adult population. PLOS One 2014;9:e84794.

18. Akinsulore A, Esimai $O$, Afolabi $O$, et al. Prevalence and factors associated with depressive symptoms among Yoruba adults in a semi-urban community in south-western Nigeria. J Behav Health 2015;4:81-6.

19. Afshar S, Roderick PJ, Kowal P, et al. Multimorbidity and the inequalities of global ageing: a cross-sectional study of 28 countries using the world health surveys. BMC Public Health 2015;15:1.

20. Roberts KC, Rao DP, Bennett TL, et al. Prevalence and patterns of chronic disease multimorbidity and associated determinants in Canada. Health Promot Chronic Dis Prev Can 2015;35:87-94.

21. Taylor AW, Price K, Gill TK, et al. Multimorbidity - not just an older person's issue. Results from an Australian biomedical study. BMC Public Health 2010;10:1.

22. Marengoni A, Angleman S, Melis R, et al. Aging with multimorbidity: a systematic review of the literature. Ageing Res Rev 2011;10:430-9.

23. Orueta JF, Nuño-Solinís R, García-Alvarez A, et al. Prevalence of multimorbidity according to the deprivation level among the elderly in the Basque country. BMC Public Health 2013;13:918.

24. Roca M, Gili M, Garcia-Garcia M, et al. Prevalence and comorbidity of common mental disorders in primary care. J Affect Disord 2009;119:52-8.

25. Naqvi $\mathrm{H}$, Khan MM. Depression in primary care: difficulties and paradoxes. J Pak Med Assoc 2005;55:393-8.

26. Uijen AA, van de Lisdonk EH. Multimorbidity in primary care: prevalence and trend over the last 20 years. Eur J Gen Pract 2008;14 Suppl 1:28-32.

27. Lockett $\mathrm{H}$, Lai J, Tuason C, et al. Primary healthcare utilisation among adults with mood and anxiety disorders: an analysis of the New Zealand health survey. J Prim Health Care 2018;10:68-75.

28. Simon GE, VonKorff M, Barlow W. Health care costs of primary care patients with recognized depression. Arch Gen Psychiatry 1995;52:850-6.

29. Ali B, Amanullah S. Prevalence of anxiety and depression in an urban squatter settlement of karachi. J Coll Physicians Surg Pak 2000;10:4-6.

30. Waheed A, Hameed K, Khan AM, et al. The burden of anxiety and depression among patients with chronic rheumatologic disorders at a tertiary care hospital clinic in Karachi, Pakistan. J Pak Med Assoc 2006;56:243-7. 
31. Smith DJ, Court H, McLean G, et al. Depression and multimorbidity: a cross-sectional study of $1,751,841$ patients in primary care. J Clin Psychiatry 2014;75:1202-8.

32. Ali BS. Validation of an Indigenous screening questionnaire for anxiety and depression in an urban squatter settlement of karachi. $J$ Coll Physicians Surg Pak 1998;8:207-11.

33. Ali BS, Reza H, Khan MM, et al. Development of an Indigenous screening instrument in Pakistan: the Aga Khan university anxiety and depression scale. J Pak Med Assoc 1998;48:261-5

34. Hosmer Jr DW, Lemeshow S, Sturdivant RX. Applied logistic regression. John Wiley \& Sons, 2013.

35. von Elm E, Altman DG, Egger M, et al. The strengthening the reporting of observational studies in epidemiology (STROBE) statement: guidelines for reporting observational studies. PLoS Med 2007;4:e296.

36. Luni FK, Ansari B, Jawad A, et al. Prevalence of depression and anxiety in a village in Sindh. J Ayub Med Coll Abbottabad 2009;21:68-72.

37. Muhammad Gadit AA, Mugford G. Prevalence of depression among households in three capital cities of Pakistan: need to revise the mental health policy. PLoS One 2007;2:e209.

38. Islam MM, Ali M, Ferroni P, et al. Prevalence of psychiatric disorders in an urban community in Bangladesh. Gen Hosp Psychiatry 2003;25:353-7.

39. Kessler RC, Berglund P, Demler O, et al. The epidemiology of major depressive disorder: results from the National comorbidity survey replication (NCS-R). JAMA 2003;289:3095-105.

40. Papadopoulos FC, Petridou E, Argyropoulou S, et al. Prevalence and correlates of depression in late life: a population based study from a rural Greek town. Int J Geriatr Psychiatry 2005;20:350-7.

41. Patel V, Prince M. Ageing and mental health in a developing country: who cares? qualitative studies from Goa, India. Psychol Med 2001;31:29-38.

42. Mirza I, Jenkins R. Risk factors, prevalence, and treatment of anxiety and depressive disorders in Pakistan: systematic review. BMJ 2004;328.

43. Patten SB. Long-Term medical conditions and major depression in a Canadian population study at waves 1 and 2. J Affect Disord 2001;63:35-41.
44. Patten SB. An analysis of data from two general health surveys found that increased incidence and duration contributed to elevated prevalence of major depression in persons with chronic medical conditions. J Clin Epidemiol 2005;58:184-9.

45. Patten SB, Wang JL, Williams JVA, et al. Descriptive epidemiology of major depression in Canada. Can J Psychiatry 2006;51:84-90.

46. Spangenberg L, Forkmann T, Brähler E, et al. The association of depression and multimorbidity in the elderly: implications for the assessment of depression. Psychogeriatrics 2011;11:227-34.

47. Katon WJ. Clinical and health services relationships between major depression, depressive symptoms, and general medical illness. Biol Psychiatry 2003;54:216-26.

48. Zahidie A, Jamali T. An overview of the predictors of depression among adult Pakistani women. J Coll Physicians Surg Pak 2013;23.

49. Husain N, Creed F, Tomenson B. Depression and social stress in Pakistan. Psychol Med 2000;30:395-402.

50. Lovisi GM, López JRRA, Coutinho ESF, et al. Poverty, violence and depression during pregnancy: a survey of mothers attending a public hospital in Brazil. Psychol Med 2005;35:1485-92.

51. Harpham T. Urbanization and mental health in developing countries: a research role for social scientists, public health professionals and social psychiatrists. Soc Sci Med 1994;39:233-45.

52. Hussain M, Saud A. Socio-Economic determinants of working children: evidence from Capital Territory of Islamabad, Pakistan. Pak Adm Rev 2017;1:145-58.

53. Nisar N, Billoo N, Gadit AA. Prevalence of depression and the associated risks factors among adult women in a fishing community. J Pak Med Assoc 2004;54:519-25.

54. Costello DM, Swendsen J, Rose JS, et al. Risk and protective factors associated with trajectories of depressed mood from adolescence to early adulthood. J Consult Clin Psychol 2008;76:173-83.

55. Lankarani MM, Assari S. Association between number of comorbid medical conditions and depression among individuals with diabetes; race and ethnic variations. J Diabetes Metab Disord 2015;14:1.

56. Mishra N, Nagpal SS, Chadda RK, et al. Help-Seeking behavior of patients with mental health problems visiting a tertiary care center in North India. Indian J Psychiatry 2011;53:234.

57. Mubbashar MH, Saeed K. Development of mental health services in Pakistan. East Mediterr Health J 2001;7:392-6. 